\title{
Diagnosis and management of migraine in ten steps
}

\author{
Anna K. Eigenbrodt $\mathbb{1}^{1,36}$, Håkan Ashina ${ }^{1,36}$, Sabrina Khan (1) ${ }^{1}$, Hans-Christoph Diener (1) ${ }^{2}$, \\ Dimos D. Mitsikostas ${ }^{3}$, Alexandra J. Sinclair (1),5,6,7, Patricia Pozo-Rosich ${ }^{8,9}$, \\ Paolo Martelletti (10,11, Anne Ducros (1) ${ }^{12}$, Michel Lantéri-Minet ${ }^{13}$, Mark Braschinsky (iD ${ }^{14}$, \\ Margarita Sanchez del Rio ${ }^{15}$, Oved Daniel (10 ${ }^{16}$, Aynur Özge (1D ${ }^{17}$, Ayten Mammadbayli ${ }^{18}$, \\ Mihails Arons $\mathbb{D}^{19}$, Kirill Skorobogatykh $\mathbb{1}^{20}{ }^{2}$, Vladimir Romanenko ${ }^{21}$, Gisela M. Terwindt ${ }^{22}$, \\ Koen Paemeleire $\mathbb{1}^{23}$, Simona Sacco $\mathbb{B}^{24}$, Uwe Reuter $\mathbb{B}^{25}$, Christian Lampl26,27,

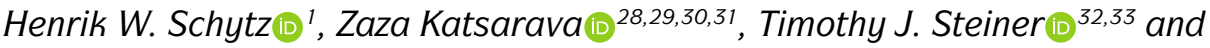 \\ Messoud Ashina ${ }^{1,31,34,35 凶}$
}

Abstract | Migraine is a disabling primary headache disorder that directly affects more than one billion people worldwide. Despite its widespread prevalence, migraine remains under-diagnosed and under-treated. To support clinical decision-making, we convened a European panel of experts to develop a ten-step approach to the diagnosis and management of migraine. Each step was established by expert consensus and supported by a review of current literature, and the Consensus Statement is endorsed by the European Headache Federation and the European Academy of Neurology. In this Consensus Statement, we introduce typical clinical features, diagnostic criteria and differential diagnoses of migraine. We then emphasize the value of patient centricity and patient education to ensure treatment adherence and satisfaction with care provision. Further, we outline best practices for acute and preventive treatment of migraine in various patient populations, including adults, children and adolescents, pregnant and breastfeeding women, and older people. In addition, we provide recommendations for evaluating treatment response and managing treatment failure. Lastly, we discuss the management of complications and comorbidities as well as the importance of planning long-term follow-up.

Migraine is a highly disabling primary headache disorder with a 1-year prevalence of $\sim 15 \%$ in the general population ${ }^{1,2}$. According to the Global Burden of Disease Study, migraine is the second most prevalent neurological disorder worldwide and is responsible for more disability than all other neurological disorders combined $^{2,3}$.

Migraine manifests clinically as recurrent attacks of headache with a range of accompanying symptoms ${ }^{4}$. In approximately one third of individuals with migraine, headache is sometimes or always preceded or accompanied by transient neurological disturbances, referred to as migraine aura ${ }^{5,6}$. Furthermore, a minority of those affected develop chronic migraine, in which attacks become highly frequent ${ }^{7}$. The pathogenesis of migraine is widely believed to involve peripheral and central activation of the trigeminovascular system ${ }^{8}$, and cortical spreading depression is thought to be the underlying neurophysiological substrate of migraine aura ${ }^{9}$. However, much remains unknown about specific pathogenic processes and few mechanism-based treatment options currently exist ${ }^{10}$.

Treatments for migraine include acute and preventive medications and a range of non-pharmacological therapies ${ }^{10}$. Despite these treatment options and the comprehensive diagnostic criteria, clinical care remains suboptimal - misdiagnosis and under-treatment of migraine are substantial public health challenges ${ }^{11,12}$. Population-based data from Europe indicate that preventive medication for migraine is used by only $2-14 \%$ of eligible individuals ${ }^{11}$, an alarming finding that calls for global action ${ }^{12}$. A comprehensive approach is needed to facilitate accurate diagnosis and evidence-based management.

In this Consensus Statement, we provide a ten-step approach to the diagnosis and management of migraine (FIG. 1). Development of this approach was initiated by the Danish Headache Society, and the Consensus Statement is endorsed by the European Headache Federation (EHF) and the European Academy of Neurology 
(EAN). The aim of the approach is to support care and clinical decision-making by primary care practitioners, neurologists and headache specialists alike.

\begin{abstract}
Methods
The Danish Headache Society and its representatives (A.K.E., H.A., H.W.S. and M.Ashina) conceived a European Consensus Statement on the diagnosis and clinical management of migraine. A formal proposal, including a suggested list of authors, was prepared and submitted to the Board of Directors of the EHF, the Chairs of the EAN Headache Panel and the Chair of the EAN Scientific Committee. The proposal was approved by unanimous decision and a European expert panel was convened to develop this Consensus
\end{abstract}

\footnotetext{
Author addresses

${ }^{1}$ Danish Headache Center, Department of Neurology, Rigshospitalet Glostrup, Faculty of Health and Medical Sciences, University of Copenhagen, Copenhagen, Denmark. ${ }^{2}$ Institute for Medical Informatics, Biometry and Epidemiology, Medical Faculty, University Duisburg-Essen, Essen, Germany.

${ }^{3}$ First Department of Neurology, Aeginition Hospital, National and Kapodistrian University of Athens, Athens, Greece.

${ }^{4}$ Metabolic Neurology, Institute of Metabolism and Systems Research, College of Medical and Dental Sciences, University of Birmingham, Birmingham, UK.

${ }^{5}$ Birmingham Neuro-Ophthalmology, Queen Elizabeth Hospital, Birmingham, UK.

${ }^{6}$ Centre for Endocrinology, Diabetes and Metabolism, Birmingham Health Partners, Birmingham, UK.

${ }^{7}$ Department of Neurology, University Hospitals Birmingham NHS Foundation Trust, Queen Elizabeth Hospital, Birmingham, UK.

${ }^{8}$ Headache Unit, Neurology Department, Vall d'Hebron University Hospital, Barcelona, Spain.

${ }^{9}$ Headache and Neurological Pain Research Group, Vall d'Hebron Research Institute, Universitat Autònoma de Barcelona, Barcelona, Spain.

${ }^{10}$ Department of Clinical and Molecular Medicine, Sapienza University, Rome, Italy.

${ }^{11}$ Regional Referral Headache Centre, Sant'Andrea Hospital, Rome, Italy.

${ }^{12}$ Neurology Department, Montpellier University Hospital, Montpellier, France.

${ }^{13}$ Departement d'Evaluation et Traitement de la Douleur, Centre Hospitalo-Universitaire de Nice, Nice, France.

${ }^{14}$ Neurology Clinic, Tartu University Hospital, Tartu, Estonia.

${ }^{15}$ Department of Neurology, Clínica Universidad de Navarra, Madrid, Spain.

${ }^{16} \mathrm{Headache} \&$ Facial Pain Clinic, Laniado Medical Center, Netanya, Israel.

${ }^{17}$ Department of Neurology, Mersin University Medical Faculty, Mersin, Turkey.

${ }^{18}$ Department of Neurology, Azerbaijan State Medical University, Baku, Azerbaijan.

${ }^{19}$ Department of Anesthesiology and Intensive Care, P. Stradins University, Riga, Latvia.

${ }^{20}$ University Headache Clinic, Moscow, Russia.

${ }^{21}$ Ukrainian Institute of Family Medicine, Kiev, Ukraine.

${ }^{22}$ Department of Neurology, Leiden University Medical Center, Leiden, Netherlands.

${ }^{23}$ Department of Neurology, Ghent University Hospital, Ghent, Belgium.

${ }^{24}$ Neuroscience Section, Department of Applied Clinical Sciences and Biotechnology,

University of L'Aquila, L'Aquila, Italy.

${ }^{25}$ Department of Neurology, Charité Universitätsmedizin Berlin, Berlin, Germany.

${ }^{26} \mathrm{Headache}$ Medical Center, Seilerstaette Linz, Linz, Austria.

${ }^{27}$ Department of Geriatric Medicine, Ordensklinikum Linz, Linz, Austria.

${ }^{28}$ Department of Neurology, University of Duisburg-Essen, Essen, Germany.

${ }^{29}$ Department of Neurology, Evangelical Hospital Unna, Unna, Germany.

${ }^{30}$ EVEX Medical Corporation, Tbilisi, Georgia.

${ }^{31}$ Department of Nervous Diseases of the Institute of Professional Education,

IM Sechenov First Moscow State Medical University, Moscow, Russia.

${ }^{32}$ Department of Neuromedicine and Movement Science, Faculty of Medicine and Health

Sciences, NTNU Norwegian University of Science and Technology, Trondheim, Norway.

${ }^{33}$ Division of Brain Sciences, Imperial College London, London, UK.

${ }^{34}$ Danish Knowledge Center on Headache Disorders, Glostrup, Denmark.

${ }^{35}$ Department of Neurology, Azerbaijan Medical University, Baku, Azerbaijan.

${ }^{36}$ These authors contributed equally: Anna K. Eigenbrodt, Håkan Ashina.
}

Statement. Three authors (H.A., T.J.S. and M.Ashina) identified the ten most important steps in diagnosis and management of migraine through email correspondence. Once these steps were agreed, seven authors (A.K.E., H.A., S.K., H.-C.D., H.W.S., T.J.S. and M.Ashina) wrote the initial draft.

For each of the ten steps, a structured literature search was performed in April 2021 using the PubMed database. We searched for "migraine" in combination with the terms "diagnosis", "treatment", "therapies", "treatment outcome" or "prognosis". We excluded publications written in a language other than English. We also selected additional articles deemed relevant from a search of the reference lists of the originally identified articles. The content was targeted towards a broad readership of primary care practitioners, neurologists and headache specialists.

In continuous email correspondence, all authors reviewed the initial draft and contributed to all subsequent drafts. Whenever possible, recommendations were based on interpretation of findings from systematic reviews and meta-analyses, relying on expert opinion only when scientific evidence was limited or unavailable. The views of each author were taken fully into consideration and revisions were made until unanimous consensus was reached. Four rounds of review were required to establish consensus.

\section{Step 1: When to suspect migraine}

In the third edition of the International Classification of Headache Disorders (ICHD-3), migraine is classified into three main types ${ }^{4}$ : migraine without aura, migraine with aura, and chronic migraine. The clinical characteristics of each must be considered to ensure an accurate diagnosis.

Migraine without aura. Migraine without aura is characterized by recurrent headache attacks that last $4-72 \mathrm{~h}^{4}$. Typical features of an attack include a unilateral location, pulsating quality, moderate or severe pain intensity, and aggravation by routine physical activity ${ }^{4,13}$. However, bilateral pain is not uncommon; population-based data indicate that $\sim 40 \%$ of individuals with migraine report bilateral pain during attacks. The most common associated symptoms are photophobia, phonophobia, nausea and vomiting ${ }^{4,13}$. Before the onset of pain, prodromal symptoms can include a depressed mood, yawning, fatigue and cravings for specific foods ${ }^{14}$. After resolution of the headache, postdromal symptoms can last up to $48 \mathrm{~h}$ and often include tiredness, concentration difficulties and neck stiffness ${ }^{15}$.

Migraine with aura. Approximately one third of individuals with migraine experience aura ${ }^{5}$, either with every attack or with some attacks. Aura is defined as transient focal neurological symptoms that usually precede, but sometimes accompany, the headache phase of a migraine attack $^{4}$. In $>90 \%$ of affected individuals, aura manifests visually $^{4,16}$, classically as fortification spectra ${ }^{4}$. Sensory symptoms occur in $\sim 31 \%$ of affected individuals and are usually experienced as predominantly unilateral paraesthesia (pins and needles and/or numbness) that spreads gradually in the face or $\mathrm{arm}^{16}$. 
When to suspect migraine

- Recurrent headache of moderate to severe intensity

- Visual aura

- Family history of migraine

- Onset of symptoms at or around puberty

\section{Diagnosis of migraine}

- Record medical history

- Apply diagnostic criteria

- Consider differential diagnoses

- Examine patient to exclude other causes

- Use neuroimaging only when a secondary headache disorder is suspected

\begin{tabular}{l}
\hline Acute treatment \\
First-line medication \\
- NSAIDs (acetylsalicylic acid, \\
ibuprofen or diclofenac \\
potassium) \\
Second-line medication \\
- Triptans \\
- When triptans provide \\
insufficient pain relief, \\
combine with fast-acting \\
NSAIDs \\
Third-line medication \\
- Ditans \\
- Gepants \\
Adjunct medications for \\
nausea and/or vomiting \\
- Prokinetic antiemetics \\
(domperidone or \\
metoclopramide) \\
\end{tabular}

- Preventative treatment
- Recommended for patients
adversely affected on $\geq 2$ days
per month despite optimized
acute therapy
First-line medication
- Beta blockers (propranolol,
metoprolol, atenolol,
bisoprolol)
- Topiramate
- Candesartan
Second-line medication
- Flunarizine
- Amitriptyline
- Sodium valproate
Third-line medication
- CGRP monoclonal
antibodies

Patient centricity and education

- Provide appropriate reassurance

- Agree on realistic objectives

- Identify predisposing and/or trigger factors

- Follow strategy to individualize therapy according to symptoms and needs

Clinical management and follow-up

Evaluation of treatment
response and
management of failure
- Use headache calendars
- Assess effectiveness and
adverse events
- When outcomes are
suboptimal, review
diagnosis, treatment
strategy, dosing and
adherence
- When treatment fails,
re-evaluate before changing
- Referral to specialist care
should be reserved for
patients whose condition is
diagnostically challenging,
difficult to treat or
complicated by
comorbidities

Managing complications

- Discourage medication overuse and recognize and stop established medication overuse to prevent $\mathrm{MOH}$

- For $\mathrm{MOH}$, withdraw overused medication, preferably abruptly

- Specialist referral is indicated for patients with chronic migraine

- Use preventive treatment for chronic migraine: topiramate, onabotulinumtoxinA or CGRP monoclonal antibodies $^{\mathrm{b}}$

\section{Managing migraine in special populations}

Older people

- Secondary headache, comorbidities and adverse events are all more likely

- Poor evidence base for all drugs in this age group

Children and adolescents

- Be aware that presentation can differ from migraine in adults

- Parents and schools have important roles in the management of young children

- Bed rest alone can be sufficient

- Use ibuprofen for acute treatment and propranolol, amitriptyline or topiramate for prevention

Women who are pregnant or breastfeeding

- Use paracetamol for acute treatment

- Avoid preventive treatment if possible

Women with menstrual migraine

- Perimenstrual preventive therapy with long-acting NSAID or triptan

Fig. 1 | Ten-step approach to the diagnosis and management of migraine. CGRP, calcitonin gene-related peptide;

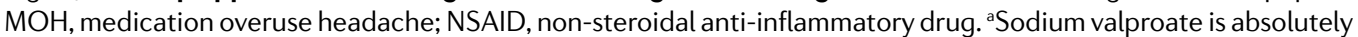
contraindicated in women of childbearing potential. ${ }^{\circ}$ CGRP monoclonal antibodies target CGRP or its receptor.

Less common aura symptoms include aphasic speech disturbance, brainstem symptoms (such as dysarthria and vertigo), motor weakness (in hemiplegic migraine) and retinal symptoms (for example, repeated monocular visual disturbances $)^{4}$. Aura symptoms can be similar to those of transient ischaemic attacks (TIA), but can be differentiated on the basis that aura symptoms often spread gradually (over $\geq 5 \mathrm{~min}$ ) and occur in succession, whereas symptoms of a TIA have a sudden, simultaneous onset ${ }^{4}$. 
Notably, migraine with aura and migraine without aura can coexist. Many individuals with migraine with aura also experience attacks that are not preceded by aura ${ }^{4}$. In such cases, migraine with aura and migraine without aura should both be diagnosed.

Chronic migraine. Chronic migraine is defined as $\geq 15$ headache days per month for $>3$ months and fulfilment of ICHD-3 criteria for migraine on $\geq 8$ days per month ${ }^{4}$. Chronic migraine is not a static entity and reversion to episodic migraine is not unusual. Similarly,

\section{Box 1 | ICHD-3 diagnostic criteria for primary headache disorders ${ }^{4}$}

\section{Migraine without aura}

1. At least five attacks that fulfil criteria $2-5$

2. Headache attacks that last $4-72 \mathrm{~h}$ when untreated or unsuccessfully treated

3. Headache has at least two of the following four characteristics: - unilateral location

- pulsating quality

- moderate or severe pain intensity

- aggravation by, or causing avoidance of, routine physical activity (for example, walking or climbing stairs)

4. At least one of the following during the headache:

- nausea and/or vomiting

- photophobia and phonophobia

5. Not better accounted for by another ICHD-3 diagnosis

Migraine with aura

1. At least two attacks that fulfil criteria 2 and 3

2. One or more of the following fully reversible aura symptoms:

- visual

- sensory

- speech and/or language

- motor

- brainstem

- retinal

3. At least three of the following six characteristics:

- at least one aura symptom spreads gradually over $\geq 5 \mathrm{~min}$

- two or more aura symptoms occur in succession

- each individual aura symptom lasts 5-60 min

- at least one aura symptom is unilateral

- at least one aura symptom is positive

- the aura is accompanied with or followed by headache within $60 \mathrm{~min}$

4. Not better accounted for by another ICHD-3 diagnosis

\section{Chronic migraine}

1. Headache (migraine-like or tension-type-like) on $\geq 15$ days/month for $>3$ months that fulfil criteria 2 and 3

2. Attacks occur in an individual who has had at least five attacks that fulfil the criteria for migraine without aura and/or for migraine with aura

3. On $\geq 8$ days/month for $>3$ months, any of the following criteria are met:

- criteria 3 and 4 for migraine without aura

- criteria 2 and 3 for migraine with aura

- believed by the patient to be migraine at onset and relieved by a triptan or ergot derivative

4. Not better accounted for by another ICHD-3 diagnosis

Medication-overuse headache

1. Headache on $\geq 15$ days/month in an individual with a pre-existing headache disorder

2. Regular overuse for $>3$ months of one or more drugs that can be taken for acute and/or symptomatic treatment of headache (regular intake of one or more non-opioid analgesics on $\geq 15$ days/month for $\geq 3$ months or any other acute medication or combination of medications on $\geq 10$ days/month for $\geq 3$ months)

3. Not better accounted for by another ICHD-3 diagnosis retransformation to chronic migraine can subsequently occur $^{17}$.

Family history of migraine. Migraine has a strong genetic component and its prevalence is higher among people with directly affected first-degree relatives than among the general population ${ }^{18,19}$. Family history is, therefore, an important part of the medical history and is often positive in patients with migraine, although it might be under-reported by patients ${ }^{20}$.

\section{Recommendations.}

- Suspect migraine without aura in a person with recurrent moderate to severe headache, particularly if pain is unilateral and/or pulsating, and when the person has accompanying symptoms such as photophobia, phonophobia, nausea and/or vomiting.

- Suspect migraine with aura in a person with the symptoms above and recurrent, short-lasting visual and/or hemisensory disturbances.

- Suspect chronic migraine in a person with $\geq 15$ headache days per month.

- Suspicion of migraine should be strengthened by a family history of migraine and if onset of symptoms is at or around puberty.

\section{Step 2: Diagnosis of migraine}

The medical history is the mainstay of migraine diagnosis; with the assistance of a range of published aids (see the section Diagnostic aids), a full history should enable systematic application of the criteria set out in the ICHD-3. Physical examination is most often confirmatory and further investigations (for example, neuroimaging, blood samples or lumbar puncture) are occasionally required to confirm or reject suspicions of secondary causes for headache.

Medical history. An adequate medical history must include at least the following: age at onset of headache; duration of headache episodes; frequency of headache episodes; pain characteristics (for example, location, quality, severity, aggravating factors and relieving factors); accompanying symptoms (for example, photophobia, phonophobia, nausea and vomiting); aura symptoms (if any); and history of acute and preventive medication use. All are essential for the application of the ICHD-3 criteria.

Diagnostic criteria. The ICHD- 3 criteria $^{4}$ (BOX 1), which were developed by the International Headache Society, set out the clinical features that establish the diagnosis of migraine and its types and subtypes. These criteria prioritize specificity over sensitivity, so an additional set of criteria are given for a diagnosis of probable migraine, which is defined as "migraine-like attacks missing one of the features required to fulfil all criteria for a type or subtype of migraine" ${ }^{\text {. }}$. Probable migraine is a diagnosis pending confirmation during early follow-up.

Diagnostic aids. Headache diaries are useful diagnostic aids that can also be used to re-evaluate the diagnosis whenever needed (BOX 2). Daily diary entries record 


\section{Box 2 | Diagnostic aids and screening tools}

\section{Headache diary}

Headache diaries are useful diagnostic aids and can also, if needed, assist with re-evaluation of diagnosis at follow-ups (see Related links for an example headache diary).

\section{Headache calendar}

Headache calendars are useful in follow-ups for recording the temporal occurrence of headaches and related events, such as menstruation (see Related links for an example headache calendar).

Three-item Identify Migraine questionnaire

The three-item Identify Migraine (ID-Migraine) questionnaire identifies individuals who are likely to have migraine on the basis of their answers to three questions regarding headache-associated nausea, photophobia and disability ${ }^{22}$.

\section{Migraine Screen Questionnaire}

The Migraine Screen Questionnaire (MS-Q), like ID-Migraine, is designed to screen patients for migraine but includes five questions regarding headache frequency, intensity and length, headache associated nausea, photophobia and phonophobia, and disability ${ }^{23}$. because some of these disorders are serious and potentially life-threatening (for example, meningitis and subarachnoid haemorrhage) (TABLE 2).

Tension-type headache (TTH) is the only other paroxysmal headache disorder that is prevalent in the general population ${ }^{28}$. TTH lacks the symptoms that accompany migraine and usually involves bilateral, mild to moderate pain with a pressing or tightening quality that is not aggravated by routine physical activity ${ }^{4,28}$ (TABLE 1).

Cluster headache is a much less prevalent primary headache disorder that affects $\sim 0.1 \%$ of the general population ${ }^{29}$. Its features are highly characteristic and include frequently recurrent but short-lasting attacks (15-180 min) of strictly unilateral headache of severe or very severe intensity ${ }^{4}$. The head pain is accompanied by ipsilateral cranial autonomic symptoms, such as conjunctival injection, lacrimation and nasal congestion ${ }^{4}$ (TABLE 1).

Medication-overuse headache $(\mathrm{MOH})$ is a secondary headache disorder that is an important differential diagnosis for chronic migraine ${ }^{30}$ (BOX 1). This disorder commonly develops from overuse of acute medication to treat migraine attacks, so the two disorders are often conflated (see Step 8 for more on $\mathrm{MOH}$ ).

Some other secondary headache disorders can present with features that suggest migraine, but specific red flags should create suspicion (TABLE 2). Red flags in the medical history include thunderclap headache, atypical aura and head trauma. Red flags in the physical examination include unexplained fever, impaired memory and focal neurological symptoms (TABLE 2). These red flags are indications for further investigation, such as neuroimaging, blood samples or lumbar puncture ${ }^{31}$.

Need for neuroimaging. The only role for neuroimaging in the diagnosis of headache is to confirm or exclude causes of secondary headache that are suspected on the basis of red flags in the medical history and/or physical examination $^{32,33}$. Otherwise, neuroimaging is not only rarely necessary in the diagnostic work-up of migraine but can be harmful, as it can involve exposure to ionizing radiation ${ }^{33,34}$. When needed for investigation of possible secondary headache disorders, MRI is preferred to CT, as it offers a higher resolution and does not involve exposure to ionizing radiation ${ }^{35,36}$. However, MRI can reveal clinically insignificant abnormalities (for example, white matter lesions, arachnoid cysts and meningiomas), which can alarm the patient and lead to further unnecessary testing ${ }^{33,37,38}$.

\section{Recommendations.}

- Take a careful medical history, applying the ICHD-3 criteria.

- Use validated diagnostic aids and screening tools, such as headache diaries, the three-item ID-Migraine questionnaire and the five-item Migraine Screen Questionnaire.

Differential diagnoses. Differential diagnoses for migraine include other primary headache disorders (TABLE 1) and some secondary headache disorders (TABLE 2). Distinction from other primary headache disorders is a prerequisite for successful management, whereas distinction from secondary headache disorders is crucial
- Consider differential diagnoses, including other primary headache disorders and secondary headache disorders.

- Use neuroimaging only when a secondary headache disorder is suspected. 
Table 1 | Characteristics of primary headache disorders

\begin{tabular}{|c|c|c|c|c|c|c|}
\hline $\begin{array}{l}\text { Headache } \\
\text { disorder }\end{array}$ & $\begin{array}{l}\text { Headache } \\
\text { duration }\end{array}$ & $\begin{array}{l}\text { Headache } \\
\text { location }\end{array}$ & Pain intensity & $\begin{array}{l}\text { Pain } \\
\text { characteristics }\end{array}$ & Accompanying symptoms & $\begin{array}{l}\text { Routine physical } \\
\text { activity }\end{array}$ \\
\hline Migraine & $4-72 \mathrm{~h}$ & Usually unilateral & $\begin{array}{l}\text { Usually moderate } \\
\text { or severe }\end{array}$ & $\begin{array}{l}\text { Usually } \\
\text { pulsating }\end{array}$ & $\begin{array}{l}\text { Photophobia, phonophobia, } \\
\text { nausea, vomiting }\end{array}$ & $\begin{array}{l}\text { Often aggravated } \\
\text { by routine physical } \\
\text { activity }\end{array}$ \\
\hline $\begin{array}{l}\text { Tension-type } \\
\text { headache }\end{array}$ & $\begin{array}{l}\text { Hours to } \\
\text { days or } \\
\text { unremitting }\end{array}$ & $\begin{array}{l}\text { Usually bilateral or } \\
\text { circumferential }\end{array}$ & $\begin{array}{l}\text { Usually mild or } \\
\text { moderate }\end{array}$ & $\begin{array}{l}\text { Usually pressing } \\
\text { or tightening }\end{array}$ & $\begin{array}{l}\text { Often none; sometimes } \\
\text { photophobia or phonophobia } \\
\text { (but not both); sometimes mild } \\
\text { nausea in chronic tension-type } \\
\text { headache }\end{array}$ & $\begin{array}{l}\text { Not aggravated by } \\
\text { routine physical } \\
\text { activity }\end{array}$ \\
\hline $\begin{array}{l}\text { Cluster } \\
\text { headache }\end{array}$ & $15-180 \mathrm{~min}$ & $\begin{array}{l}\text { Strictly unilateral } \\
\text { and orbital, } \\
\text { supraorbital, } \\
\text { and/or temporal }\end{array}$ & $\begin{array}{l}\text { Severe or very } \\
\text { severe }\end{array}$ & Overwhelming & $\begin{array}{l}\text { Ipsilateral to the headache: } \\
\text { cranial autonomic symptoms, } \\
\text { such as conjunctival injection, } \\
\text { lacrimation, and nasal congestion }\end{array}$ & $\begin{array}{l}\text { Restlessness or } \\
\text { agitation }\end{array}$ \\
\hline
\end{tabular}

\section{Step 3: Education and patient centricity}

Patient centricity and education have important roles in the management of migraine. Indeed, optimal outcomes are unlikely when these aspects are not given sufficient attention.

Explanation, reassurance and objectives. Patient satisfaction is a key management outcome and treatment success depends on it but most people with migraine report at least one perceived unmet treatment need ${ }^{39}$. Unrealistic expectations constitute a major obstacle to achieving patient satisfaction - a common misconception among patients is that effective treatment means cure of their migraine ${ }^{32,40}$. Clinicians must therefore disabuse patients of this belief without being overly negative. A realistic objective is a return of control from the disease to the patient with treatment that mitigates attackrelated disability (by reducing attack frequency, attack duration and/or pain intensity) to an extent that the patient can continue with life with as little hindrance as possible.

Non-adherence is also an obstacle to effective treatment $^{41}$ and requires management. Education is the solution - clinicians must explain to the patient both the disease and the principles of managing it effectively, including instruction on the correct use of medication, potential adverse effects and what to do about them, and the importance of avoiding medication overuse. Such education can require time that is not available, but freely available patient information leaflets can support patient education ${ }^{32}$.

Predisposing factors and triggers. Contrary to popular belief, predisposing and trigger factors are of limited importance in migraine, and their role is often overemphasized ${ }^{42}$. An important exception is menstruation, as some women's migraine attacks are exclusively or frequently menstruation-related. True trigger factors are often selfevident. Moreover, aggravating factors should not be conflated with predisposing factors. The former worsen headache during migraine attacks (for example, physical activity), whereas predisposing factors increase susceptibility to the development of a migraine attack (for example, poor sleep quality, poor physical fitness or stress).

Nevertheless, if predisposing and trigger factors can be correctly identified and subsequently avoided (which is often not possible), some headache control might be achievable without further intervention ${ }^{43}$. For instance, lifestyle changes can benefit patients with poor sleep quality or physical fitness, though any changes should not result in unnecessary avoidance behaviour, which can itself damage quality of life.

Individualized therapy. Multiple effective acute and preventive therapies are available for migraine. When selecting from these therapies, the objective is that each patient receives the therapy that provides the best personal outcome. Unfortunately, no a priori basis for selection currently exists, at least for acute therapy. Optimal individualized therapy is therefore currently best achieved with a stepped care approach, set out in detail in Step 4.

\section{Recommendations.}

- Provide every patient with a full explanation of migraine as a disease and of the principles of its management.

- Consider predisposing and trigger factors, but keep in mind that true trigger factors are often self-evident.

- Adhere to the principles of stepped care to achieve optimal individualized therapy (see Step 4).

\section{Step 4: Acute treatment}

Acute treatments can be classified as first-line, second-line, third-line and adjunct (TABLE 3), and should be used in a stepped care approach ${ }^{32}$ (FIG. 2). Our recommendations for each line of treatment are outlined below. The medications at each stage were selected on the basis of efficacy, tolerability, safety, cost and availability.

First-line medication. Over-the-counter analgesics are used worldwide for acute migraine treatment ${ }^{44}$. Those with proven efficacy include non-steroidal anti-inflammatory drugs (NSAIDs), and the strongest evidence supports use of acetylsalicylic acid, ibuprofen and diclofenac potassium as first-line medications $\mathrm{s}^{45-47}$. Paracetamol has less efficacy ${ }^{48}$ and should be used only in those who are intolerant of NSAIDs.

Second-line medication. Patients for whom over-thecounter analgesics provide inadequate headache relief should be offered a triptan. All triptans have welldocumented effectiveness, but availability of and access 
to each vary between countries. Triptans are most effective when taken early in an attack, when the headache is still mild ${ }^{49,50}$. However, no evidence supports the use of triptans during the aura phase of a migraine attack. If one triptan is ineffective, others might still provide relief $f^{51,52}$. When all other triptans have failed or in patients who rapidly reach peak headache intensity or cannot take oral triptans because of vomiting, sumatriptan by subcutaneous injection can be useful ${ }^{53}$.

Some patients can experience relapses, which are defined as a return of symptoms within $48 \mathrm{~h}$ after apparently successful treatment. Upon relapse, patients can repeat their triptan treatment or combine the triptan with simultaneous intake of fast-acting formulations of naproxen sodium, ibuprofen lysine or diclofenac potassium ${ }^{54,55}$. However, patients should be informed that repeating the treatment does not preclude further relapses and ultimately increases the risk of developing $\mathrm{MOH}$.

Third-line medication. If all available triptans fail after an adequate trial period (no or insufficient therapeutic response in at least three consecutive attacks) or their use is contraindicated, alternatives are currently limited. Ditans or gepants could be used, but their availability is currently very limited. Lasmiditan is the only ditan approved for acute treatment of migraine, and ubrogepant and rimegepant are the only gepants approved. Indirect comparison of data from randomized controlled trials suggests that the efficacy of lasmiditan is comparable to that of triptans ${ }^{56-58}$, but its use is associated with temporary driving impairment, which is likely to discourage widespread use. Individuals who take

Table 2 | Red flags associated with secondary headaches ${ }^{31,32}$

\begin{tabular}{|c|c|c|}
\hline When to look & Red flag & Indication \\
\hline \multirow[t]{8}{*}{ Patient history } & Thunderclap headache & Subarachnoid haemorrhage \\
\hline & Atypical aura & $\begin{array}{l}\text { Transient ischaemic attack, } \\
\text { stroke, epilepsy, arteriovenous } \\
\text { malformations }\end{array}$ \\
\hline & Head trauma & Subdural haematoma \\
\hline & Progressive headache & Intracranial space-occupying lesion \\
\hline & $\begin{array}{l}\text { Headache aggravated by } \\
\text { postures or manoeuvres that } \\
\text { raise intracranial pressure }\end{array}$ & $\begin{array}{l}\text { Intracranial hypertension or } \\
\text { hypotension }\end{array}$ \\
\hline & $\begin{array}{l}\text { Headache brought on by } \\
\text { sneezing, coughing or exercise }\end{array}$ & Intracranial space-occupying lesion \\
\hline & $\begin{array}{l}\text { Headache associated with } \\
\text { weight loss and/or change } \\
\text { in memory or personality }\end{array}$ & Suggests secondary headache \\
\hline & $\begin{array}{l}\text { Headache onset at }>50 \text { years } \\
\text { of age }\end{array}$ & $\begin{array}{l}\text { Suggests secondary headache; } \\
\text { consider temporal arteritis }\end{array}$ \\
\hline \multirow{5}{*}{$\begin{array}{l}\text { Physical } \\
\text { examination }\end{array}$} & Unexplained fever & Meningitis \\
\hline & Neck stiffness & $\begin{array}{l}\text { Meningitis, subarachnoid } \\
\text { haemorrhage }\end{array}$ \\
\hline & Focal neurological symptoms & Suggests secondary headache \\
\hline & Weight loss & Suggests secondary headache \\
\hline & $\begin{array}{l}\text { Impaired memory and/or altered } \\
\text { consciousness or personality }\end{array}$ & Suggests secondary headache \\
\hline
\end{tabular}

lasmiditan might be unable to self-assess their driving competence and should not operate machinery for at least $8 \mathrm{~h}$ after intake.

Adjunct medication. For patients who experience nausea and/or vomiting during migraine attacks, prokinetic antiemetics such as domperidone and metoclopramide are useful oral adjuncts.

Medications to avoid. Oral ergot alkaloids are poorly effective and potentially toxic, and should not be used as a substitute for triptans ${ }^{59}$. The efficacy of opioids and barbiturates is questionable, and both are associated with considerable adverse effects and the risk of dependency ${ }^{60}$. All of these medications should, therefore, be avoided for the acute treatment of migraine.

\section{Recommendations.}

- Offer acute medication to everyone who experiences migraine attacks.

- Advise use of acute medications early in the headache phase of the attack, as effectiveness depends on timely use with the correct dose.

- Advise patients that frequent, repeated use of acute medication risks development of $\mathrm{MOH}$.

- Use NSAIDs (acetylsalicylic acid, ibuprofen or diclofenac potassium) as first-line medication.

- Use triptans as second-line medication.

- Consider combining triptans with fast-acting NSAIDs to avert recurrent relapse.

- Consider ditans and gepants as third-line medications.

- Use prokinetic antiemetics (domperidone or metoclopramide) as adjunct oral medications for nausea and/or vomiting.

- Avoid oral ergot alkaloids, opioids and barbiturates.

\section{Step 5: Preventive treatment}

Initiation and termination. In patients whose migraine continues to impair their quality of life despite optimized acute therapy, additional preventive therapy should be considered (TABLE 4). In practice, patients who are considered for preventive treatment remain adversely affected on at least 2 days per month ${ }^{32}$, although this should not be regarded as an absolute rule ${ }^{32}$. Aside from migraine frequency, clinicians should always consider factors such as the severity of attacks, the duration of attacks (for example, menstruation-related attacks tend to last longer) and migraine-related disability. A further indication for preventive therapy is overuse of acute medication.

Efficacy of preventive therapy is rarely observed immediately. Only after several weeks or months can efficacy be ascertained, so patients should be discouraged from abandoning the treatment in these early stages on the grounds of apparent inefficacy ${ }^{32}$. If a therapeutic dose of an oral preventive medication is ineffective after 2-3 months, an alternative should be tried ${ }^{32,61,62}$. For monoclonal antibody treatments that target calcitonin gene-related peptide (CGRP) or its receptor, efficacy should be assessed only after 3-6 months. For onabotulinumtoxinA, efficacy should be assessed after 6-9 months. 
Failure of one preventive treatment does not predict failure of treatment with other drug classes, except when failure is due to poor adherence. Treatment adherence is often very poor but can be improved by simplified dosing schedules (once daily or less) ${ }^{32}$. For most preventive medications, clinical experience suggests that pausing can be considered when treatment has been successful for 6-12 months ${ }^{32}$. The purpose of pausing is to ascertain whether preventive treatment can be stopped, which minimizes the risk of unnecessary drug exposure and allows some patients to manage their migraine with acute medications only. A useful measure to quantify the degree of preventive treatment success is to calculate the percentage reduction in monthly migraine

Table 3 | Acute migraine treatment

\begin{tabular}{|c|c|c|c|}
\hline Drug class & Drug & Dosage and route & Contraindications \\
\hline \multicolumn{4}{|c|}{ First-line medication } \\
\hline \multirow[t]{3}{*}{ NSAIDs } & $\begin{array}{l}\text { Acetylsalicylic } \\
\text { acid }\end{array}$ & $900-1,000 \mathrm{mg}$ oral & \multirow[t]{3}{*}{$\begin{array}{l}\text { Gastrointestinal } \\
\text { bleeding, heart failure }\end{array}$} \\
\hline & Ibuprofen & $400-600 \mathrm{mg}$ oral & \\
\hline & $\begin{array}{l}\text { Diclofenac } \\
\text { potassium }\end{array}$ & 50 mg oral (soluble) & \\
\hline $\begin{array}{l}\text { Other simple } \\
\text { analgesics } \\
\text { (if NSAIDs are } \\
\text { contraindicated) }\end{array}$ & Paracetamol & $1,000 \mathrm{mg}$ oral & $\begin{array}{l}\text { Hepatic disease, renal } \\
\text { failure }\end{array}$ \\
\hline \multirow[t]{2}{*}{$\begin{array}{l}\text { Antiemetics } \\
\text { (when necessary) }\end{array}$} & Domperidone & $\begin{array}{l}10 \mathrm{mg} \text { oral or } \\
\text { suppository }\end{array}$ & $\begin{array}{l}\text { Gastrointestinal } \\
\text { bleeding, epilepsy, } \\
\text { renal failure, cardiac } \\
\text { arrhythmia }\end{array}$ \\
\hline & Metoclopramide & $10 \mathrm{mg}$ oral & $\begin{array}{l}\text { Parkinson disease, } \\
\text { epilepsy, mechanical } \\
\text { ileus }\end{array}$ \\
\hline \multicolumn{4}{|c|}{ Second-line medication } \\
\hline \multirow[t]{7}{*}{ Triptans } & Sumatriptan & $\begin{array}{l}50 \text { or } 100 \mathrm{mg} \text { oral or } \\
6 \mathrm{mg} \text { subcutaneous } \\
\text { or } 10 \text { or } 20 \mathrm{mg} \\
\text { intranasal }\end{array}$ & \multirow{7}{*}{$\begin{array}{l}\text { Cardiovascular or } \\
\text { cerebrovascular } \\
\text { disease, uncontrolled } \\
\text { hypertension, } \\
\text { hemiplegic migraine, } \\
\text { migraine with } \\
\text { brainstem aura }\end{array}$} \\
\hline & Zolmitriptan & $\begin{array}{l}2.5 \text { or } 5 \mathrm{mg} \text { oral or } \\
5 \mathrm{mg} \text { intranasal }\end{array}$ & \\
\hline & Almotriptan & $12.5 \mathrm{mg}$ oral & \\
\hline & Eletriptan & 20,40 or $80 \mathrm{mg}$ oral & \\
\hline & Frovatriptan & $2.5 \mathrm{mg}$ oral & \\
\hline & Naratriptan & $2.5 \mathrm{mg}$ oral & \\
\hline & Rizatriptan & $\begin{array}{l}10 \mathrm{mg} \text { oral tablet } \\
(5 \mathrm{mg} \text { if treated with } \\
\text { propranolol) or } 10 \mathrm{mg} \\
\text { mouth-dispersible } \\
\text { wafers }\end{array}$ & \\
\hline \multicolumn{4}{|c|}{ Third-line medication } \\
\hline \multirow[t]{2}{*}{ Gepants } & Ubrogepant & $50,100 \mathrm{mg}$ oral & $\begin{array}{l}\text { Co-administration } \\
\text { with strong CYP3A4 } \\
\text { inhibitors }\end{array}$ \\
\hline & Rimegepant & $75 \mathrm{mg}$ oral & $\begin{array}{l}\text { Hypersensitivity, } \\
\text { hepatic impairment }\end{array}$ \\
\hline Ditans & Lasmiditan & $\begin{array}{l}50,100 \text { or } 200 \mathrm{mg} \\
\text { oral }\end{array}$ & $\begin{array}{l}\text { Pregnancy, concomitant } \\
\text { use with drugs that } \\
\text { are P-glycoprotein } \\
\text { substrates }\end{array}$ \\
\hline
\end{tabular}

days or monthly headache days of moderate-to-severe intensity. However, a pragmatic approach is needed and clinicians should decide to pause preventive therapy on a case-by-case basis.

Current standard of care. As for acute medications, preventive treatments can be classified as first-line, second-line and third-line options (TABLE 4). However, choice of medication and the order of use depend on local practice guidelines and local availability, costs and reimbursement policies.

First-line medications are beta blockers without intrinsic sympathomimetic activity (atenolol, bisoprolol, metoprolol or propranolol) ${ }^{63}$, topiramate ${ }^{64}$ and candesartan ${ }^{65,66}$. If these fail, second-line medications include flunarizine ${ }^{67}$, amitriptyline ${ }^{68}$ and sodium valproate $^{69}$, although valproate is strictly contraindicated in women of childbearing potential, which greatly limits its utility in migraine ${ }^{70-72}$. Third-line medications are the four CGRP monoclonal antibodies erenumab, fremanezumab, galcanezumab and eptinezumab. These antibodies have been approved for the preventive treatment of migraine in the past few years ${ }^{61}$. In Europe, regulatory restrictions limit their use to patients in whom other preventive drugs have failed or are contraindicated ${ }^{61}$.

Non-pharmacological therapies. A range of nonpharmacological preventive therapies can be used either as adjuncts to acute and preventive medications or instead of them if medication use is contraindicated. Some evidence supports the use of non-invasive neuromodulatory devices ${ }^{73}$, biobehavioural therapy ${ }^{74}$ and acupuncture ${ }^{75}$, although a study of acupuncture indicated that it is not superior to sham acupuncture ${ }^{76}$. Contrary to popular belief, little to no evidence exists for physical therapy ${ }^{77}$, spinal manipulation and dietary approaches ${ }^{78}$. We make no recommendations about other therapeutic options, such as melatonin, magnesium and riboflavin, as limited evidence for their efficacy is available and their use in clinical practice is limited.

\section{Recommendations.}

- Consider preventive treatment in patients who are adversely affected by migraine on $\geq 2$ days per month despite optimized acute treatment.

- Use beta blockers (atenolol, bisoprolol, metoprolol or propranolol), topiramate or candesartan as first-line medications.

- Use flunarizine, amitriptyline or (in men) sodium valproate as second-line medications.

- Consider CGRP monoclonal antibodies as third-line medications.

- Consider neuromodulatory devices, biobehavioural therapy and acupuncture as adjuncts to acute and preventive medication or as stand-alone preventive treatment when medication is contraindicated.

Step 6: Managing migraine in special populations Older people. Migraine often remits with older age whereas the incidence of many secondary headaches increases $^{79-81}$. Onset of apparent migraine after the age of 50 years should, therefore, arouse suspicion of an 


\section{CONSENSUS STATEMENT}

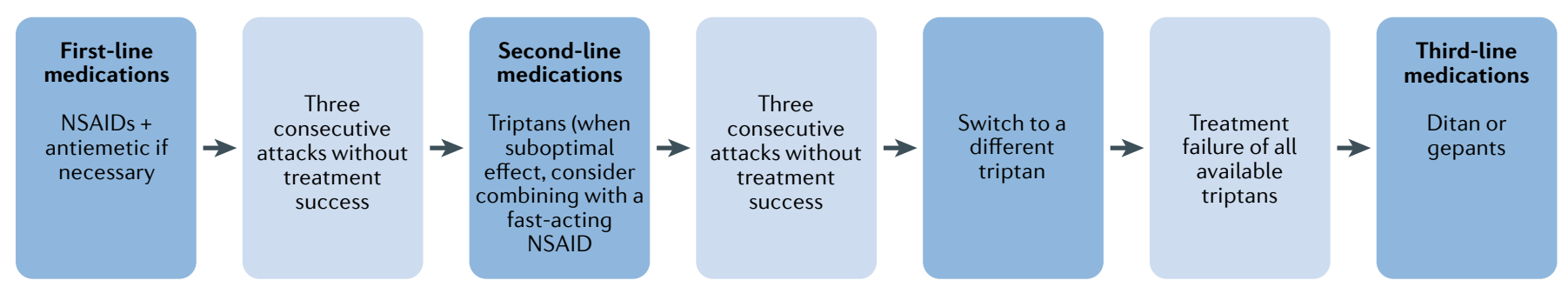

Fig. 2 | Stepped care across migraine attacks. Preventive therapy, in addition, may be indicated at any stage. In general, initiation of preventive therapy is indicated in patients who are adversely affected on $\geq 2$ days per month despite acute treatment optimized according to the stepped care approach. NSAID, non-steroidal anti-inflammatory drug.

underlying cause. In individuals whose migraine persists from earlier life into later years, clinical management often remains unchanged in practice. Little formal evidence is available with respect to therapeutic approaches in older people with migraine.

Nonetheless, known and possible unknown comorbidities need to be considered, as well as harm that might be caused by drug-specific adverse effects ${ }^{82}$, to which older people are generally more susceptible. For instance, use of triptans in older people is often advised against owing to the relatively high likelihood that these patients have cardiovascular disease and/or cardiovascular risk factors. However, no robust evidence supports an increased risk of cerebrovascular or cardiovascular events in older people owing to triptan use per $\mathrm{se}^{83}$. Nonetheless, clinicians are advised to regularly monitor blood pressure in older patients with migraine who use triptans, in addition to periodical assessment of cardiovascular risk factors ${ }^{84}$.

Children and adolescents. Migraine is common among children and its prevalence increases in adolescence ${ }^{85}$. As in adults, diagnosis is primarily based on the medical history, although the criteria are slightly different - the duration of migraine attacks can be 2 to $72 \mathrm{~h}^{4}$. The clinical features of migraine in children and adolescents also differ somewhat from those in adults - the attacks are often shorter ${ }^{4}$, the headache is more often bilateral and less often pulsating, and gastrointestinal disturbances are commonly prominent ${ }^{32}$. Descriptions of these features might be more reliably provided by parents than children, and parents will also provide a better account of lifestyle factors that might need to be addressed ${ }^{86}$.

In children and young adolescents, clinical management usually requires active help from family members and teachers ${ }^{86}$, so education of both is necessary. Bed-rest alone might suffice in children with attacks that have a short duration. When needed, ibuprofen is recommended as first-line medication, at a dose appropriate for body weight ${ }^{32}$. Domperidone can be used for nausea in adolescents aged $12-17$ years $^{87}$, although oral administration is unlikely to prevent vomiting.

The evidence base for medication therapy in children and adolescents is confounded by a high placebo response in clinical trials ${ }^{88,89}$. As a consequence, the apparent therapeutic gain is low, and this effect probably explains why a benefit of triptans has not been demonstrated in children. For adolescents aged 12-17 years, multiple NSAIDs and triptans have been approved for acute treatment of migraine ${ }^{90,91}$, and some evidence indicates that nasal spray formulations of sumatriptan and zolmitriptan are the most effective ${ }^{92}$. If acute medication provides insufficient pain relief, referral to specialist care is indicated ${ }^{32}$. In practice, propranolol, amitriptyline and topiramate are used for preventive treatment, although their effectiveness in children and adolescents has not been proven in clinical trials ${ }^{88,89}$.

Pregnant and breastfeeding women. Migraine often remits during pregnancy, but if treatment is continued, the potential for harm to the fetus demands special consideration $^{93}$. Despite relatively poor efficacy, paracetamol should be used as the first-line medication for acute treatment of migraine in pregnancy ${ }^{48}$; NSAIDs can be used only during the second trimester ${ }^{93,94}$. Triptans should be used only under the strict supervision of a specialist, as the safety data available are limited and originate from post-marketing surveillance; most data relate to the use of sumatriptan ${ }^{32}$. For nausea associated with migraine in pregnancy, metoclopramide can be used ${ }^{94,95}$.

Preventive migraine medications are best avoided during pregnancy owing to the potential for fetal harm. However, if preventive therapy is considered clinically indicated because of frequent and disabling migraine attacks, the best available safety data support the use of propranolol or, if propranolol is contraindicated, amitriptyline. Both should be used under specialist supervision to adequately monitor any potential fetal harm $^{32}$. Topiramate, candesartan and sodium valproate are contraindicated; sodium valproate is known to be teratogenic, so must not be used ${ }^{70,94}$, and the use of topiramate and candesartan is associated with adverse effects on the fetus.

Migraine medication therapy in the post-partum period also requires caution because of potential risks to the infant. Paracetamol is the preferred acute medication, although ibuprofen and sumatriptan are also considered safe ${ }^{94}$. If preventive medication is required, propranolol is the recommended first choice as it has the best safety profile ${ }^{94}$. Pharmacological treatments for migraine during pregnancy and breastfeeding have been reviewed in more detail elsewhere ${ }^{94}$.

Women with menstrual migraine. Approximately $8 \%$ of women with migraine experience migraine attacks that are exclusively related to their menstruation, referred to as pure menstrual migraine ${ }^{96,97}$. If optimized acute medication therapy does not suffice for these patients, 


\begin{tabular}{|c|c|c|c|}
\hline Drug class & Drug & Dosage and route & Contraindications \\
\hline \multicolumn{4}{|c|}{ First-line medication } \\
\hline \multirow[t]{4}{*}{ Beta blockers } & Atenolol & 25-100 mg oral twice daily & \multirow{4}{*}{$\begin{array}{l}\text { Asthma, cardiac failure, Raynaud } \\
\text { disease, atrioventricular block, } \\
\text { depression }\end{array}$} \\
\hline & Bisoprolol & 5-10 mg oral once daily & \\
\hline & Metoprolol & $\begin{array}{l}50-100 \text { mg oral twice daily or } \\
200 \text { mg modified-release oral } \\
\text { once daily }\end{array}$ & \\
\hline & Propranolol & $\begin{array}{l}80-160 \mathrm{mg} \text { oral once or twice daily } \\
\text { in long-acting formulations }\end{array}$ & \\
\hline $\begin{array}{l}\text { Angiotensin } \\
\text { II-receptor blocker }\end{array}$ & Candesartan & 16-32 mg oral per day & Co-administration of aliskiren \\
\hline Anticonvulsant & Topiramate & 50-100 mg oral daily & $\begin{array}{l}\text { Nephrolithiasis, pregnancy, } \\
\text { lactation, glaucoma }\end{array}$ \\
\hline \multicolumn{4}{|c|}{ Second-line medication } \\
\hline $\begin{array}{l}\text { Tricyclic } \\
\text { antidepressant }\end{array}$ & Amitriptyline & $10-100 \mathrm{mg}$ oral at night & $\begin{array}{l}\text { Age }<6 \text { years, heart failure, } \\
\text { co-administration with monoamine } \\
\text { oxidase inhibitors and SSRIs, } \\
\text { glaucoma }\end{array}$ \\
\hline Calcium antagonist & Flunarizine & 5-10 mg oral once daily & Parkinsonism, depression \\
\hline Anticonvulsant & Sodium valproate ${ }^{a}$ & $600-1,500 \mathrm{mg}$ oral once daily & $\begin{array}{l}\text { Liver disease, thrombocytopenia, } \\
\text { female and of childbearing } \\
\text { potential }\end{array}$ \\
\hline \multicolumn{4}{|l|}{ Third-line medication } \\
\hline Botulinum toxin & OnabotulinumtoxinA & $\begin{array}{l}155-195 \text { units to } 31-39 \text { sites every } \\
12 \text { weeks }\end{array}$ & Infection at injection site \\
\hline \multirow{5}{*}{$\begin{array}{l}\text { Calcitonin } \\
\text { gene-related } \\
\text { peptide monoclonal } \\
\text { antibodies }\end{array}$} & Erenumab & 70 or $140 \mathrm{mg}$ subcutaneous once & \multirow{5}{*}{$\begin{array}{l}\text { Hypersensitivity } \\
\text { Not recommended in patients } \\
\text { with a history of stroke, } \\
\text { subarachnoid haemorrhage, } \\
\text { coronary heart disease, } \\
\text { inflammatory bowel disease, } \\
\text { chronic obstructive pulmonary } \\
\text { disease or impaired wound healing }\end{array}$} \\
\hline & & & \\
\hline & Fremanezumab & $\begin{array}{l}225 \text { mg subcutaneous once } \\
\text { monthly or } 675 \text { mg subcutaneous } \\
\text { once quarterly }\end{array}$ & \\
\hline & Galcanezumab & $\begin{array}{l}240 \mathrm{mg} \text { subcutaneous, then } 120 \mathrm{mg} \\
\text { subcutaneous once monthly }\end{array}$ & \\
\hline & Eptinezumab & $\begin{array}{l}100 \text { or } 300 \mathrm{mg} \text { intravenous } \\
\text { quarterly }\end{array}$ & \\
\hline
\end{tabular}

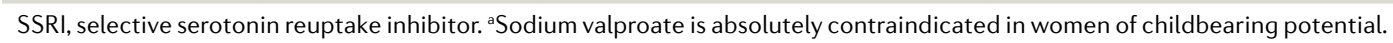

initiation of perimenstrual preventive treatment should be considered. This approach typically involves daily intake of a long-acting NSAID (for example, naproxen) or triptan (for example, frovatriptan or naratriptan) for 5 days, beginning 2 days before the expected first day of menstruation ${ }^{98-101}$. Some women with pure menstrual migraine without aura benefit from continuous use (that is, without a break) of combined hormonal contraceptives. By contrast, combined hormonal contraceptives are contraindicated in women with migraine with aura regardless of any association with their menstrual cycle, owing to an associated increase in the risk of stroke ${ }^{32}$.

\section{Recommendations.}

- In patients with apparent late-onset migraine, suspect an underlying cause.

- In older people, consider the higher risks of secondary headache, comorbidities and adverse events with older age.

- In children and adolescents with migraine, bed rest alone might suffice; if not, use ibuprofen for acute treatment and propranolol, amitriptyline or topiramate for prevention.
- In pregnant or breastfeeding women, use paracetamol for acute treatment and avoid preventive medication whenever possible.

- In women with menstrual migraine, consider perimenstrual preventive therapy with a long-acting NSAID or triptan.

\section{Step 7: Follow-up, treatment response and failure}

Active follow-up is the only appropriate means of determining outcome and provides the opportunity to review both diagnosis and treatment strategies. The response to treatment should be evaluated within 2-3 months after initiation or a change in treatment, and regularly thereafter, though not necessarily at short intervals (for example, 6-12 months). Evaluation of treatment responses should include a review of effectiveness, adverse events and adherence.

Key outcome measures for effectiveness are attack frequency, attack severity and migraine-related disability ${ }^{32}$. Attack frequency is usually measured in headache or migraine days per month. Severity is usually expressed as pain intensity rather than functional consequence, which should be separately assessed. Headache calendars 
are extremely useful for capturing these measures and require little time commitment if completed only on symptomatic days ${ }^{32}$. In addition, headache calendars are valuable for monitoring acute medication use. At follow-up assessments, the self-administered Migraine Treatment Optimization Questionnaire (mTOQ-4) can be used to evaluate the effectiveness of acute medications ${ }^{102}$, whereas the self-completed eight-item HURT questionnaire (Headache Under-Response to Treatment) can be used to assess the effectiveness of an intervention and generates suggestions for changes to improve effectiveness ${ }^{103}$ (BOX 3).

When treatment fails. A conclusion that treatment has failed should be made with caution and must always be preceded by a thorough review of the underlying reasons. In some cases, apparent failures might be remediable, such as when failure is due to poor adherence or suboptimal dosing ${ }^{32}$. Whereas some patients benefit from higher doses, others might benefit from lower doses that have fewer adverse effects and therefore improve adherence. Alternatives when first-line medications fail are outlined above (see Step 4 and Step 5). If all treatments fail, the diagnosis should be questioned and specialist referral is indicated ${ }^{32}$.

When specialist referral is needed. Approximately $90 \%$ of people who seek professional care for migraine should be treated in primary care ${ }^{104}$. Referral to specialist care should be reserved for the minority of patients whose condition is diagnostically challenging, difficult to treat or complicated by comorbidities ${ }^{32}$. Specialist care provides access to greater expertise maintained by experience and to multidisciplinary care. However, specialist capacity is limited and the cost is much higher ${ }^{105}$.

\section{Recommendations.}

- Evaluate treatment responses shortly after initiation (after 2-3 months) or a change of treatment and regularly thereafter (every 6-12 months).

- Evaluate the effectiveness of treatment by assessing attack frequency, attack severity and migraine-related disability.

- When outcomes are suboptimal, review the diagnosis, treatment strategy, dosing and adherence.

- If all treatment fails, question the diagnosis and consider specialist referral.

\section{Box $3 \mid$ Tools for evaluation of treatment response}

\section{HURT questionnaire}

The Headache Under-Response to Treatment (HURT) questionnaire is an eight-item, self-administered questionnaire developed specifically to guide follow-up in primary care $^{103}$. The questionnaire assesses treatment outcome in several domains, and responses are coupled to suggested changes in management. It has been validated for clinical use in English and Arabic ${ }^{133,134}$ and is available online in 12 languages (see Related links for where to access the HURT questionnaire).

\section{mTOQ-4}

The Migraine Treatment Optimization Questionnaire (mTOQ-4) is a self-administered questionnaire that can be used to assess acute treatment, including treatment efficacy ${ }^{102}$ This questionnaire has been validated for use in primary care and used in several studies to assess treatment outcomes ${ }^{102,118,135}$.

\section{Step 8: Managing complications}

Medication overuse headache. $\mathrm{MOH}$ is a chronic headache disorder characterized by headache on $\geq 15$ days per month. It develops over a variable period of time in patients with a pre-existing headache disorder as a result of regular overuse of acute or symptomatic headache medication ${ }^{4}$. Patients with migraine account for approximately two thirds of all cases of $\mathrm{MOH}$, although this estimate is based on limited evidence and might be too low $^{106}$.

Withdrawal of the overused medication is the necessary and only remedy for $\mathrm{MOH}^{107}$. Expert consensus is that abrupt withdrawal is preferable to slow withdrawal, except for opioids ${ }^{30}$. This process can be managed in primary care unless addictive drugs, such as opioids, are involved ${ }^{108,109}$. Patient education is a key component of the clinical management of $\mathrm{MOH}$, as withdrawal is usually followed by worsening before recovery ${ }^{30,110}$. Preventive therapy (pharmacological and/or non-pharmacological) appropriate to the antecedent headache can be started in parallel with acute medication withdrawal or upon re-emergence of the headache disorder ${ }^{30}$, although this topic remains a subject of debate $\mathrm{e}^{111,112}$.

Transformation to chronic migraine. Some estimates suggest that up to $3 \%$ of patients with episodic migraine experience transformation to chronic migraine each year $^{113}$. The reliability of such estimates is uncertain because chronic migraine is often conflated with $\mathrm{MOH}^{114}$, but transformation to chronic migraine does occur. Recognized risk factors include female sex, a high headache frequency, inadequate treatment, overuse of acute medications and a range of comorbidities, including depression, anxiety and obesity ${ }^{115-118}$. Recognition of these risk factors is part of good clinical management, as their modification can prevent transformation.

Once chronic migraine has developed, its management is challenging and referral to specialist care is usually necessary ${ }^{32}$. If $\mathrm{MOH}$, which frequently causes symptoms that suggest chronic migraine, can be ruled out, then a preventive treatment should be established ${ }^{114}$. Individuals with chronic migraine should also be educated on the modifiable risk factors for chronic migraine so that they can make lifestyle changes that might help.

Preventive medications for which evidence supports effectiveness in chronic migraine include topiramate ${ }^{119}$, onabotulinumtoxin $\mathrm{A}^{120}$ and CGRP monoclonal antibodies $^{121}$. Topiramate is the drug of first choice owing to its much lower cost. Regulatory restrictions generally limit the use of onabotulinumtoxinA and CGRP antibodies to patients in whom two or three other preventive medications have failed, despite the fact that topiramate is the only other treatment with evidence supporting its use. Three CGRP antibodies (erenumab, fremanezumab and galcanezumab) have been proven to be beneficial for patients in whom at least two other preventive medications have failed ${ }^{122-124}$. As in episodic migraine, the choice of preventive medication and their order of use depends on local practice guidelines, availability, cost and reimbursement policies. No robust data 
from random controlled trials support the use of beta blockers, candesartan or amitriptyline for the preventive treatment of chronic migraine, although they are commonly used in clinical practice.

\section{Recommendations.}

- Educate patients with migraine about the risk of $\mathrm{MOH}$ with frequent overuse of acute medication.

- Manage established MOH by explanation and withdrawal of the overused medication; abrupt withdrawal is preferred, except for opioids.

- Recognize and, when possible, modify risk factors for the transformation of episodic migraine to chronic migraine.

- Refer patients with chronic migraine to specialist care.

- Once MOH is ruled out, initiate preventive medication therapy for chronic migraine; evidence-based treatment options are topiramate, onabotulinumtoxin A and CGRP monoclonal antibodies.

\section{Step 9: Recognizing and managing comorbidities}

Migraine is associated with anxiety, depression, sleep disturbances and chronic pain conditions (for example, neck and lower back pain) ${ }^{125-129}$. These associations are more pronounced in people with chronic migraine than in those with episodic migraine ${ }^{130}$. Obesity is also an important risk factor for transformation from episodic migraine to chronic migraine and should be accounted for in the clinical evaluation ${ }^{131}$. Furthermore, migraine with aura has been associated with cardiovascular events in women ${ }^{132}$.

Recognition of comorbid conditions in migraine is important because they can influence drug choice. For example, topiramate is the preferred treatment for patients with obesity owing to its association with weight loss. For patients with depression or sleep disturbances, amitriptyline is most likely to be of benefit. Recognition of comorbidities is also important because their alleviation can improve treatment outcomes for migraine, and vice versa.

\section{Recommendations.}

- Ensure that comorbidities are identified in patients with migraine, as they can affect treatment choice and outcomes.

- Adjust treatments accordingly and consider possible interactions between drug-related adverse effects and the patient's comorbidity profile.

\section{Step 10: Long-term follow-up}

Long-term management of migraine should be the responsibility of primary care. Referral from specialist care back to primary care should be timely, coordinated with the general practitioner and accompanied by a comprehensive treatment plan that includes recommendations for re-evaluation and steps to be taken for each of the likely outcomes. In general, timely return to primary care can be made once the patient experiences sustained efficacy with preventive therapy for up to 6 months with no substantial treatment-related adverse effects.

In primary care, the main goal of follow-up is to maintain stability of adequate outcomes, whether achieved in primary or specialist care, and to react appropriately to any change that might call for review. Neither purpose requires regular routine contact, which should, therefore, be avoided unless necessary in the context of repeat prescriptions. Instead, primary care physicians should emphasize patient education and self-efficacy with respect to judging when a return visit is necessary.

\section{Recommendations.}

- Primary care should be responsible for the long-term management of patients with migraine, maintaining stability and reacting to change.

- Referral from specialist back to primary care should be timely and accompanied by a comprehensive treatment plan.

- The patient can be referred back to primary care once sustained efficacy with preventive therapy for up to 6 months is obtained with no substantial treatment-related adverse effects.

\section{Conclusions}

Migraine is a ubiquitous neurological disorder that adds substantially to the global burden of disease. Despite the existence of comprehensive diagnostic criteria and a multitude of therapeutic options, diagnosis and clinical management of migraine remain suboptimal worldwide. This Consensus Statement was developed by experts from Europe to provide generally applicable recommendations for the diagnosis and management of migraine and to promote best clinical practices. The recommendations are based on published evidence and expert opinion, and will be updated when new information and treatments emerge.

Published online 18 June 2021
1. Ashina, M. Migraine N. Engl. J. Med. 383 1866-1876 (2020)

2. GBD 2016 Neurology Collaborators. Global, regional, and national burden of neurological disorders, 1990-2016: a systematic analysis for the Global Burden of Disease Study 2016. Lancet Neurol. 18, 459-480 (2019)

3. GBD 2016 Headache Collaborators. Global, regional, and national burden of migraine and tension-type headache, 1990-2016: a systematic analysis for the Global Burden of Disease Study 2016. Lancet Neurol. 17, 954-976 (2018)

4. [No authors listed] Headache Classification Committee of the International Headache Society (IHS) the International Classification of Headache Disorders, 3rd edition. Cephalalgia 38, 1-211 (2018)

5. Rasmussen, B. K. \& Olesen, J. Migraine with aura and migraine without aura: an epidemiological study. Cephalalgia 12, 221-228 (1992).
6. Hansen, J. M. et al. Migraine headache is present in the aura phase. Neurology 79, 2044-2049 (2012).

7. Natoli, J. L. et al. Global prevalence of chronic migraine: a systematic review. Cephalalgia 30, 599-609 (2010).

8. Ashina, M. et al. Migraine and the trigeminovascular system -40 years and counting. Lancet Neurol. 18, 795-804 (2019)

9. Ashina, M. et al. Migraine: disease characterisation, biomarkers, and precision medicine. Lancet 397 , 1496-1504 (2021).

10. Ashina, M. et al. Migraine: integrated approaches to clinical management and emerging treatments. Lancet 397, 1505-1518 (2021)

11. Katsarava, Z., Mania, M., Lampl, C., Herberhold, J. \& Steiner, T. J. Poor medical care for people with migraine in Europe - evidence from the Eurolight study. J. Headache Pain 19, 10 (2018).

12. Ashina, M. et al. Migraine: epidemiology and systems of care. Lancet 397, 1485-1495 (2021).
13. Rasmussen, B. K., Jensen, R., Schroll, M. \& Olesen, J. Epidemiology of headache in a general population-a prevalence study. J. Clin. Epidemiol. 44, 1147-1157 (1991).

14. Karsan, N. \& Goadsby, P. J. Biological insights from the premonitory symptoms of migraine. Nat. Rev. Neurol. 14, 699-710 (2018).

15. Giffin, N. J., Lipton, R. B., Silberstein, S. D., Olesen, J. $\&$ Goadsby, P. J. The migraine postdrome. Neurology 87, 309-313 (2016)

16. Russell, M. B. \& Olesen, J. A nosographic analysis of the migraine aura in a general population. Brain 119 , 355-361 (1996).

17. Serrano, D. et al. Fluctuations in episodic and chronic migraine status over the course of 1 year: implications for diagnosis, treatment and clinical trial design. J. Headache Pain 18, 101 (2017).

18. Russell, M. B., Hilden, J., Sørensen, S. A. \& Olesen, J Familial occurrence of migraine without aura and 
migraine with aura. Neurology 43, 1369-1373

(1993).

19. Ulrich, V., Gervil, M., Kyvik, K. O., Olesen, J. \& Russell, M. B. Evidence of a genetic factor in migraine with aura: a population-based Danish twin study. Ann. Neurol. 45, 242-246 (1999).

20. Russell, M. B., Fenger, K. \& Olesen, J. The family history of migraine. Direct versus indirect information. Cephalalgia 16, 156-160 (1996).

21. Phillip, D., Lyngberg, A. ¿ Jensen, R. Assessment of headache diagnosis. A comparative population study of a clinical interview with a diagnostic headache diary. Cephalalgia 27, 1-8 (2007)

22. Lipton, R. B. et al. A self-administered screener for migraine in primary care: the ID Migraine validation study. Neurology 61, 375-382 (2003).

23. Láinez, M. J. A. et al. Development and validation of the migraine screen questionnaire (MS-O). Headache 45, 1328-1338 (2005)

24. Brighina, F. et al. A validation study of an Italian version of the ID Migraine: preliminary results. J. Headache Pain 6, 216-219 (2005).

25. Gil-Gouveia, R. \& Martins, I. Validation of the Portuguese version of ID-Migraine. Headache 50, 396-402 (2010).

26. Csépany, É. et al. The validation of the Hungarian version of the ID-migraine questionnaire. J. Headache Pain 19, 106 (2018).

27. Delic, D. et al. Translation and transcultural validation of migraine screening questionnaire (MS-O). Med. Arch. 72, 430-433 (2018).

28. Ashina, S. et al. Tension-type headache. Nat. Rev. Dis. Primers 7, 24 (2021).

29. Fischera, M., Marziniak, M., Gralow, I. \& Evers, S. The incidence and prevalence of cluster headache a meta-analysis of population-based studies. Cephalalgia 28, 614-618 (2008).

30. Diener, H.-C. et al. Pathophysiology, prevention, and treatment of medication overuse headache Lancet Neurol. 18, 891-902 (2019).

31. Do, T. P. et al. Red and orange flags for secondary headaches in clinical practice. Neurology 92 134-144 (2019).

32. Steiner, T. J. et al. Aids to management of headache disorders in primary care (2nd edition). J. Headache Pain 20, 57 (2019).

33. Mitsikostas, D. D. et al. European Headache Federation consensus on technical investigation for primary headache disorders. J. Headache Pain 17, 5 (2015).

34. Brenner, D. J. \& Hall, E. J. Computed tomographyan increasing source of radiation exposure. N. Engl. J. Med. 357, 2277-2284 (2007).

35. Evans, R. W. et al. Neuroimaging for migraine: the American Headache Society systematic review and evidence-based guideline. Headache 60, 318-336 (2019).

36. Sandrini, G. et al. Neurophysiological tests and neuroimaging procedures in non-acute headache (2nd edition). Eur. J. Neurol. 18, 373-381 (2011).

37. Callaghan, B. C., Kerber, K. A., Pace, R. J., Skolarus, L. E. \& Burke, J. F. Headaches and neuroimaging: high utilization and costs despite guidelines. JAMA Intern. Med. 174, 819-821 (2014)

38. Evans, R. W. Incidental findings and normal anatomical variants on MRI of the brain in adults for primary headaches. Headache 57, 780-791 (2017).

39. Lipton, R. B. et al. Unmet acute treatment needs from the 2017 Migraine in America Symptoms and Treatment Study. Headache 59, 1310-1323 (2019).

40. Munksgaard, S. B. et al. What do the patients with medication overuse headache expect from treatment and what are the preferred sources of information? J. Headache Pain 12, 91-96 (2011).

41. Hepp, Z. et al. Adherence to oral migraine-preventive medications among patients with chronic migraine. Cephalalgia 35, 478-488 (2015)

42. Lipton, R. B., Pavlovic, J. M., Haut, S. R., Grosberg, B. M. $\&$ Buse, D. C. Methodological issues in studying trigger factors and premonitory features of migraine. Headache 54, 1661-1669 (2014)

43. Marmura, M. J. Triggers, protectors, and predictors in episodic migraine. Curr. Pain Headache Rep. 22, 81 (2018).

44. World Health Organization. Atlas of headache disorders and resources in the world 2011 (WHO, 2011)

45. Kirthi, V., Derry, S. \& Moore, R. A. Aspirin with or without an antiemetic for acute migraine headaches in adults. Cochrane Database Syst. Rev. 4, CD008041 (2013)

46. Rabbie, R., Derry, S. \& Moore, R. A. Ibuprofen with or without an antiemetic for acute migraine headaches in adults. Cochrane Database Syst. Rev. 4, CD008039 (2013).
47. Derry, S., Rabbie, R. \& Moore, R. A. Diclofenac with or without an antiemetic for acute migraine headaches in adults. Cochrane Database Syst. Rev. 2, CD008783 (2012).

48. Derry, S. \& Moore, R. A. Paracetamol (acetaminophen) with or without an antiemetic for acute migraine headaches in adults. Cochrane Database Syst. Rev. 4 CD008040 (2013)

49. Goadsby, P. J. et al. Early vs. non-early intervention in acute migraine - 'Act when Mild (AwM)'. A doubleblind, placebo-controlled trial of almotriptan. Cephalalgia 28, 383-391 (2008).

50. Lantéri-Minet, M., Mick, G. \& Allaf, B. Early dosing and efficacy of triptans in acute migraine treatment the TEMPO study. Cephalalgia 32, 226-235 (2012).

51. Färkkilä, M. et al. Eletriptan for the treatment of migraine in patients with previous poor response or tolerance to oral sumatriptan. Cephalalgia $\mathbf{2 3}$, 463-471 (2003)

52. Dahlöf, C. G. H. Infrequent or non-response to oral sumatriptan does not predict response to other triptans-review of four trials. Cephalalgia 26, 98-106 (2006).

53. Derry, C. J., Derry, S. \& Moore, R. A. Sumatriptan (all routes of administration) for acute migraine attacks in adults - overview of Cochrane reviews. Cochrane Database Syst. Rev. 20145 , CD009108 (2014).

54. Law, S., Derry, S. \& Moore, R. A. Sumatriptan plus naproxen for the treatment of acute migraine attacks in adults. Cochrane Database Syst. Rev. 4, CD00854 (2016).

55. [No authors listed] Treatment of migraine attacks with sumatriptan. The Subcutaneous Sumatriptan International Study Group. N. Engl. J. Med. 325, 316-321 (1991)

56. Lipton, R. B. et al. Rimegepant, an oral calcitonin gene-related peptide receptor antagonist, for migraine. N. Engl. J. Med. 381, 142-149 (2019).

57. Lipton, R. B. et al. Effect of ubrogepant vs placebo on pain and the most bothersome associated symptom in the acute treatment of migraine: the ACHIEVE II randomized clinical trial. JAMA 322, 1887-1898 (2019)

58. Goadsby, P. J. et al. Phase 3 randomized, placebocontrolled, double-blind study of lasmiditan for acute treatment of migraine. Brain 142, 1894-1904 (2019).

59. Tfelt-Hansen, P. C. \& Koehler, P. J. History of the use of ergotamine and dihydroergotamine in migraine from 1906 and onward. Cephalalgia 28, 877-886 (2008).

60. Bigal, M. E. \& Lipton, R. B. Excessive opioid use and the development of chronic migraine. Pain 142 179-182 (2009)

61. Sacco, S. et al. European Headache Federation guideline on the use of monoclonal antibodies acting on the calcitonin gene related peptide or its receptor for migraine prevention. J. Headache Pain 20, 6 (2019)

62. Bendtsen, $L$ et al Guideline on the use of onabotulinumtoxinA in chronic migraine: a consensus statement from the European Headache Federation. J. Headache Pain 19, 91 (2018).

63. Jackson, J. L. et al. Beta-blockers for the prevention of headache in adults, a systematic review and meta-analysis. PLOS ONE 14, e0212785 (2019).

64. Linde, M., Mulleners, W. M., Chronicle, E. P. \& McCrory, D. C. Topiramate for the prophylaxis of episodic migraine in adults. Cochrane Database Syst. Rev. 6, CD010610 (2013).

65. Tronvik, E., Stovner, L. J., Helde, G., Sand, T. \& Bovim, G. Prophylactic treatment of migraine with an angiotensin II receptor blocker: a randomized controlled trial. JAMA 289, 65-69 (2003).

66. Stovner, L. J. et al. A comparative study of candesartan versus propranolol for migraine prophylaxis: A randomised, triple-blind, placebo-controlled, double cross-over study. Cephalalgia 34, 523-532 (2014).

67. Stubberud, A., Flaaen, N. M., McCrory, D. C. Pedersen, S. A. \& Linde, M. Flunarizine as prophylaxis for episodic migraine: a systematic review with meta-analysis. Pain 160, 762-772 (2019).

68. Jackson, J. L. et al. Tricyclic antidepressants and headaches: systematic review and meta-analysis. $B M J$ 341, C5222 (2010)

69. Linde, M., Mulleners, W. M., Chronicle, E. P. \& McCrory, D. C. Valproate (valproic acid or sodium valproate or a combination of the two) for the prophylaxis of episodic migraine in adults. Cochrane Database Syst. Rev. 6, CD010611 (2013).

70. Vatzaki, E. et al. Latest clinical recommendations on valproate use for migraine prophylaxis in women of childbearing age: overview from European
Medicines Agency and European Headache Federation. J. Headache Pain 19, 68 (2018).

71. Dodick, D. W. et al. Topiramate versus amitriptyline in migraine prevention: a 26-week, multicenter randomized, double-blind, double-dummy, parallelgroup noninferiority trial in adult migraineurs. Clin. Ther. 31, 542-559 (2009).

72. Couch, J. R. Amitriptyline in the prophylactic treatment of migraine and chronic daily headache. Headache 51, 33-51 (2011).

73. Reuter, U., McClure, C., Liebler, E. \& Pozo-Rosich, P. Non-invasive neuromodulation for migraine and cluster headache: a systematic review of clinical trials. J. Neurol. Neurosurg. Psychiatry 90, 796-804 (2019)

74. Sullivan, A., Cousins, S. \& Ridsdale, L. Psychological interventions for migraine: a systematic review. J. Neurol. 263, 2369-2377 (2016).

75. Linde, K. et al. Acupuncture for the prevention of episodic migraine. Cochrane Database Syst. Rev. 2016, CD001218 (2016).

76. Diener, H.-C. et al. Efficacy of acupuncture for the prophylaxis of migraine: a multicentre randomised controlled clinical trial. Lancet 5, 310-316 (2006).

77. Luedtke, K., Allers, A., Schulte, L. H. \& May, A. Efficacy of interventions used by physiotherapists for patients with headache and migraine-systematic review and meta-analysis. Cephalalgia 36, 474-492 (2016).

78. Hindiyeh, N. A. et al. The role of diet and nutrition in migraine triggers and treatment: a systematic literature review. Headache 60, 1300-1316 (2020).

79. Bigal, M. E. \& Lipton, R. B. Migraine at all ages. Curr. Pain Headache Rep. 10, 207-213 (2006).

80. Bigal, M. E., Liberman, J. N. \& Lipton, R. B. Age-dependent prevalence and clinical features of migraine. Neurology 67, 246-251 (2006).

81. Bamford, C. C., Mays, M. \& Tepper, S. J. Unusual headaches in the elderly. Curr. Pain Headache Rep. 15, 295-301 (2011).

82. Vongvaivanich, K., Lertakyamanee, P., Silberstein, S. D. $\&$ Dodick, D. W. Late-life migraine accompaniments: a narrative review. Cephalalgia 35, 894-911 (2015).

83. Diener, H.-C. The risks or lack thereof of migraine treatments in vascular disease. Headache 60 649-653 (2020)

84. World Health Organization. Prevention of Cardiovascular Disease: Guidelines for assessment and management of cardiovascular risk (WHO, 2007).

85. Barnes, N. P. Migraine headache in children. BMJ Clin Evid. 2015, 0318 (2015)

86. Hershey, A. D. Current approaches to the diagnosis and management of paediatric migraine. Lancet Neurol. 9, 190-204 (2010).

87. Oskoui, M. et al. Practice guideline update summary: acute treatment of migraine in children and adolescents: report of the Guideline Development, Dissemination, and Implementation Subcommittee of the American Academy of Neurology and the American Headache Society. Neurology 93, 487-499 (2019).

88. Oskoui, M. et al. Practice guideline update summary: pharmacologic treatment for pediatric migraine prevention: report of the Guideline Development, Dissemination, and Implementation Subcommittee of the American Academy of Neurology and the American Headache Society. Neurology 93, 500-509 (2019).

89. Evers, S., Marziniak, M., Frese, A. \& Gralow, I. Placebo efficacy in childhood and adolescence migraine: an analysis of double-blind and placebocontrolled studies Cephalalgia 29, 436-444 (2009).

90. Faber, A. J., Lagman-Bartolome, A. M. \& Rajapakse, T. Drugs for the acute treatment of migraine in children and adolescents. Paediatr. Child Health 22, 454-458 (2017).

91. Orr, S. L. et al. Paediatric migraine: evidence-based management and future directions. Nat. Rev. Neurol. 14, 515-527 (2018)

92. Richer, L. et al. Drugs for the acute treatment of migraine in children and adolescents. Cochrane Database Syst. Rev 4, CD005220 (2016).

93. Goadsby, P. J., Goldberg, J. \& Silberstein, S. D. Migraine in pregnancy. BMJ 336, 1502-1504 (2008).

94. Amundsen, S., Nordeng, H., Nezvalová-Henriksen, K. Stovner L J \& Spigset, O Pharmacological treatment of migraine during pregnancy and breastfeeding. Nat. Rev. Neurol. 11, 209-219 (2015).

95. Pasternak, B., Svanström, H., Mølgaard-Nielsen, D. Melbye, M. \& Hviid, A. Metoclopramide in pregnancy and risk of major congenital malformations and fetal death. JAMA 310, 1601-1611 (2013).

96. Vetvik, K. G. \& Russell, M. B. Are menstrual and nonmenstrual migraine attacks different? Curr. Pain Headache Rep. 15, 339-342 (2011). 
97. Vetvik, K. G., Macgregor, E. A., Lundqvist, C. \& Russell, M. B. Prevalence of menstrual migraine: a population-based study. Cephalalgia 34, 280-288 (2014).

98. Newman, L. et al. Naratriptan as short-term prophylaxis of menstrually associated migraine: a randomized, double-blind, placebo-controlled study. Headache $\mathbf{4 1}$ 248-256 (2001).

99. Silberstein, S. \& Patel, S. Menstrual migraine: an updated review on hormonal causes, prophylaxis and treatment. Expert Opin. Pharmacother. 15, 2063-2070 (2014)

100. van Dijkman, S. C., de Jager, N. C. B., Rauwé, W. M., Danhof, M. \& Della Pasqua, O. Effect of age-related factors on the pharmacokinetics of lamotrigine and potential implications for maintenance dose optimisation in future clinical trials. Clin. Pharmacokinet. 57, 1039-1053 (2018)

101. Silberstein, S. D. et al. Evidence-based guideline update: pharmacologic treatment for episodic migraine prevention in adults. Neurology 78, 1337-1345 (2012).

102. Lipton, R. B. et al. Validity and reliability of the migraine-treatment optimization questionnaire. Cephalalgia 29, 751-759 (2009).

103. Steiner, T. J. et al. The headache under-response to treatment (HURT) questionnaire, an outcome measure to guide follow-up in primary care: development, psychometric evaluation and assessment of utility. J. Headache Pain 19, 15 (2018).

104. Steiner, T. J. et al. Recommendations for headache service organisation and delivery in Europe. J. Headache Pain 12, 419-426 (2011).

105. World Health Organization. Building the economic case for primary health care: a scoping review. Technical series on primary health care (WHO, 2018).

106. GBD 2016 Disease and Injury Incidence and Prevalence Collaborators. Global, regional, and national incidence, prevalence, and years lived with disability for 328 diseases and injuries for 195 countries, 1990-2016: a systematic analysis for the Global Burden of Disease Study 2016. Lancet 390, 1211-1259 (2017).

107. Diener, H. C. et al. European Academy of Neurology guideline on the management of medication-overuse headache. Eur. J. Neurol. 27, 1102-1116 (2020).

108. Kristoffersen, E. S. et al. Brief intervention for medication-overuse headache in primary care. The BIMOH study: a double-blind pragmatic cluster randomised parallel controlled trial. J. Neurol. Neurosurg. Psychiatry 86, 505-512 (2015).

109. Kristoffersen, E. S. et al. Brief intervention by general practitioners for medication-overuse headache, followup after 6 months: a pragmatic cluster-randomised controlled trial. J. Neurol. 263, 344-353 (2016).

110. Lai, J. T. F. et al. Should we educate about the risks of medication overuse headache? J. Headache Pain 15, 10 (2014).

111. Pijpers, J. A. et al. Acute withdrawal and botulinum toxin A in chronic migraine with medication overuse a double-blind randomized controlled trial. Brain 142 , 1203-1214 (2019).

112. Carlsen, L. N. et al. Comparison of 3 treatment strategies for medication overuse headache: a randomized clinical trial. JAMA Neurol. 77 1069-1078 (2020)

113. Buse, D. C. et al. Chronic migraine prevalence, disability, and sociodemographic factors: results from the American Migraine Prevalence and Prevention Study. Headache 52, 1456-1470 (2012).

114. Diener, H.-C. et al. Chronic migraine - classification, characteristics and treatment. Nat. Rev. Neurol. 8 , 162-171 (2012)

115. Buse, D. C., Greisman, J. D., Baigi, K. \& Lipton, R. B. Migraine progression: a systematic review. Headache 59, 306-338 (2019).

116. Probyn, K. et al. Prognostic factors for chronic headache: a systematic review. Neurology 89, 291-301 (2017)

117. Xu, J., Kong, F. \& Buse, D. C. Predictors of episodic migraine transformation to chronic migraine: a systematic review and meta-analysis of observational cohort studies. Cephalalgia 40, 503-516 (2019).

118. Lipton, R. B. et al. Ineffective acute treatment of episodic migraine is associated with new-onset chronic migraine. Neurology 84, 688-695 (2015).

119. Silberstein, S. et al. Topiramate treatment of chronic migraine: a randomized, placebo-controlled trial of quality of life and other efficacy measures. Headache 49, 1153-1162 (2009).

120. Herd, C. P. et al. Botulinum toxins for the prevention of migraine in adults. Cochrane Database Syst. Rev. 6 CD011616 (2018).
121. Charles, A. \& Pozo-Rosich, P. Targeting calcitonin generelated peptide: a new era in migraine therapy. Lancet 394, 1765-1774 (2019)

122. Reuter, U. et al. Efficacy and tolerability of erenumab in patients with episodic migraine in whom two-to-four previous preventive treatments were unsuccessful: a randomised, double-blind, placebo-controlled, phase 3b study. Lancet 392, 2280-2287 (2018).

123. Ferrari, M. D. et al. Fremanezumab versus placebo for migraine prevention in patients with documented failure to up to four migraine preventive medication classes (FOCUS): a randomised, double-blind, placebocontrolled, phase 3b trial. Lancet 394, 1030-1040 (2019).

124. Ruff, D. D. et al. Efficacy of galcanezumab in patients with episodic migraine and a history of preventive treatment failure: results from two global randomized clinical trials. Eur. J. Neurol. 27, 609-618 (2020).

125. Dresler, T. et al. Understanding the nature of psychiatric comorbidity in migraine: a systematic review focused on interactions and treatment implications. J. Headache Pain 20,51 (2019).

126. Lampl, C. et al. Headache, depression and anxiety: associations in the Eurolight project. J. Headache Pain 17, 59 (2016).

127. Buse, D. C. et al. Sleep disorders among people with migraine: results from the chronic migraine epidemiology and outcomes (CaMEO) study. Headache 59, 32-45 (2019).

128. Ashina, S. et al. Increased pain sensitivity in migraine and tension-type headache coexistent with low back pain: A cross-sectional population study. Eur. J. Pain 22, 904-914 (2018).

129. Ashina, S. et al. Prevalence of neck pain in migraine and tension-type headache: a population study. Cephalalgia 35, 211-219 (2015).

130. Buse, D. C., Manack, A., Serrano, D., Turkel, C \& Lipton, R. B. Sociodemographic and comorbidity profiles of chronic migraine and episodic migraine sufferers. J. Neurol. Neurosurg. Psychiatry $\mathbf{8 1}$, 428-432 (2010)

131. Bigal, M. E. \& Lipton, R. B. Obesity is a risk factor for transformed migraine but not chronic tension-type headache. Neurology 67, 252-257 (2006).

132. Kurth, T., Schürks, M., Logroscino, G. \& Buring, J. E. Migraine frequency and risk of cardiovascular disease in women. Neurology 73, 581-588 (2009).

133. Westergaard, M. L. S. et al. The headache underresponse to treatment (HURT) questionnaire: assessment of utility in headache specialist care. Cephalalgia 33, 245-255 (2013).

134. Al Jumah, M. et al. HURT (Headache Under-Response to Treatment) questionnaire in the management of primary headache disorders: reliability, validity and clinical utility of the Arabic version. J. Headache Pain 14, 16 (2013)

135. Lipton, R., Manack, A., Serrano, D. \& Buse, D. Acute treatment optimization for migraine: results of the American Migraine Prevalence and Prevention (AMPP) study. J. Headache Pain 14, P201 (2013).

\section{Author contributions}

A.K.E., H.A. and M.A. researched data for the article. Al authors made substantial contributions to discussion of the content, contributed to writing and reviewed and edited the manuscript before submission.

\section{Competing interests}

S.K. has been an invited speaker for Novartis. H.-C.D. has received honoraria for participation in clinical trials, contribution to advisory boards or oral presentations from Alder Allergan, Amgen, Electrocore, Ipsen, Lilly, Medtronic, Novartis, Pfizer, Teva and Weber $\&$ Weber. Electrocore has provided financial support for his research projects. The German research council (DFG), the German ministry of Education and Research (BMBF) and the European Union support his headache research. He also serves on the editorial boards of Cephalalgia and Lancet Neurology, chairs the clinical guidelines committee of the German Society of Neurology and is a member of the Clinical Trials Committee of the International Headache Society. D.D.M. has received honoraria, research and travel grants from Allergan, Amgen, Biogen, Cefaly, Eli Lilly, Electrocore, Mertz, Novartis, Roche, Sanofi, Specifar and Teva. A.J.S. reports personal fees from Allergan and Novartis, grants from Novartis, and grants and personal fees from Invex Therapeutics. He is a trustee of the board of the International Headache Society and a member of the Council of the European Headache Federation. P.P.-R. has received honoraria as a consultant and speaker for Allergan, Almirall, Biohaven, Chiesi, Eli Lilly, Medlink, Medscape, Neurodiem, Novartis and Teva. Her research group has received research grants from Allergan, AGAUR, la Caixa foundation, EraNET Neuron, FEDER RISC3CAT, Migraine Research Foundation, Instituto Investigaciôn Carlos III,
MICINN, Novartis and PERIS, and has received funding for clincal trials from Alder Amgen, Electrocore, Eli Lilly, Novartis and Teva. She is the founder of www.midolordecabeza.org, a trustee of the board of the International Headache Society and a member of the Council of the European Headache Federation. She is on the editorial board of Revista de Neurologia, an associate editor for Cephalalgia, Frontiers of Neurology and Journal of Headache and Pain. She is also a member of the Clinical Trials Guidelines Committee of the International Headache Society and has edited the Guidelines for the Diagnosis and Treatment of Headache of the Spanish Neurological Society. P.M. has served on advisory boards for Allergan, Lilly, Novartis and Teva. $\mathrm{He}$ has received royalties from Springer Nature and travel support from the European Medicines Agency, and serves as Editor-in-Chief for Journal of Headache and Pain. A.D. reports consultant fees from Eli Lilly, Novartis and Teva. She also serves as President of the French Headache Society. M.L.-M. reports personal fees for advisory boards, speaker panels or investigation studies from Allergan, Amgen, Astellas, ATI, BMS, Boehringer, Boston Scientific, CoLucid, Convergence, GlaxoSmithKline, Grunenthal, Lilly, Medtronic, Menarini, MSD, Novartis, Pfizer, ReckittBenckiser, Saint-Jude, Sanofi-Aventis, Teva, UCB and Zambon. M.S.d.R. reports consultant fees as a speaker or participation on advisory boards from Allergan, Eli-Lilly, Novartis and Teva. G.M.T. reports consultant fees from Amgen, Eli Lilly, Novartis and Teva, and has received grant support from the Dutch Brain Foundation, Dutch Heart Foundation, NIH, NOW and ZonMW. K.P. has received honoraria as a speaker and/or consultant, and/or received research support from Allergan, Amgen/Novartis, Autonomic Technologies, Eli-Lilly and Teva. S.S. reports fees as a speaker or consultant for Allergan, Abbott, Eli-Lilly, Novartis and Teva. She is also an associate editor for Stroke and serves as co-editor for Journal of Headache and Pain. U.R. has received consulting fees, speaking or teaching fees and/or research grants from Allergan, Amgen, Autonomic Technologies, CoLucid, ElectroCore and Novartis. H.W.S. has received consultant fees for lectures from Eli-Lilly, Novartis and TEVA. He has received consultant fees for advisory board participation from Balancair and Eli Lilly, and has received funding from Novartis. Z.K. has been a speaker and/or consultant, and/or received research support from Allergan, Amgen/Novartis, Ely-Lilly, Merck and Teva. T.J.S. reports personal fees from Eli Lilly. M.A. has received personal fees from Alder BioPharmaceuticals, Allergan, Amgen, Eli-Lilly, Novartis and Teva. He has been or is currently a principal investigator on clinical trials for Alder, Amgen, ElectroCore, Novartis and Teva. He serves as Associate Editor of Cephalalgia, Headache and Journal of Headache and Pain. He also reports research grants from Lundbeck Foundation, Novo Nordisk Foundation, and Research Foundation of the Capital Region of Denmark. The other authors report no competing interests.

Peer review information

Nature Reviews Neurology thanks J. Rothrock, A. Tinsley and the other, anonymous, reviewer(s) for their contribution to the peer review of this work.

\section{Publisher's note}

Springer Nature remains neutral with regard to jurisdictional claims in published maps and institutional affiliations.

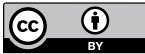

Open Access This article is licensed under a Creative Commons Attribution 4.0 International License, which permits use, sharing, adaptation, distribution and reproduction in any medium or format, as long as you give appropriate credit to the original author(s) and the source, provide a link to the Creative Commons license, and indicate if changes were made. The images or other third party material in this article are included in the article's Creative Commons license, unless indicated otherwise in a credit line to the material. If material is not included in the article's Creative Commons license and your intended use is not permitted by statutory regulation or exceeds the permitted use, you will need to obtain permission directly from the copyright holder. To view a copy of this license, visit http://creativecommons.org/licenses/by/4.0/

\section{RELATED LINKS}

Example headache calendar: https://static-conte
com/esm/art\%3A10.1186\%2Fs10194-018-0899-2 com/esm/art\%3A10.1186\%2Fs10194-018-0899-2/ Example headache diary: https://static-content.spring com/esm/art\%3A10.1186\%2Fs10194-018-0899-2/ MediaObjects/10194_2018_899_MOESM16_ESM.pd HURT questionnaire: https://migraine-acute-treatment.ime. springerhealthcare.com/wp-content/uploads/EN-HURT.pdf
Patient information leaflets: https://static-content.springer. com/esm/art\%3A10.1186\%2Fs10194-018-0899-2/ MediaObjects/10194_2018_899_MOESM21_ESM.pdf

(c) The Author(s) 2021 